\title{
The Forestry Sector - A Presentation to the Special Joint Committee Reviewing Canadian Foreign Policy
}

\author{
On July 27, 1994, the CIF presented a comprehensive \\ report on the significance of the forestry sector on \\ Canadian foreign policy to the Special Joint Committee \\ Reviewing Canadian Foreign Policy.
}

\begin{abstract}
The verbal, summary remarks of the 42-page document are recorded in Hansard for further reference. The recommendations presented are as follows:
\end{abstract}

\begin{abstract}
Foreign Aid Assistance
It is recommended that:

i. Forestry and conservation remain a priority for Canada's international development assistance programs utilizing the extensive talents of expertise in the public and private sectors.

ii. To respond to the increasing need for assistance to sustainably manage the forest resources of developing manage the forest resources of developing countries, development assistance by Canada be delivered through the NFAP process (National Forest Action Program), where possible, as an appropriate vehicle to strengthen the country capacity to plan and implement forest sector development programs.
\end{abstract}

iii. Development assistance programs increasingly emphasize networking, providing support to bringing people together to develop policy issues, building institutional capacities, and focusing on crucial issues of sustainable development (e.g., model forests program).

iv. To contribute to international cooperation to further the development of best principles of sustainable forest management in Canada and abroad, support be given to the enlargement and time frame extension through Canada's aid program of the existing international network of model forests.
Trade

It is recommended that:

v. This committee facilitate every possible support to the current efforts to obtain national and international certification for Canadian forest products, through the Standards Council of Canada and the International Standards Organization (ISO).

vi. Development assistance funds be allocated to assist third world nations to establish national certification standards that will meet ISO international principles.

vii. This committee support a consolidation of the communications strategies currently employed in international markets into a single, effective campaign to promote Canada's sustainable forest management practices abroad.

viii. This committee supports, as part of the foregoing international communications strategy, the organization of a high-profile conference on sustainability. This should have a broad focus with all the implications for the total environment.

ix. Given the critical importance to Canada and the rest of the world of achieving an international convention on sustainable forestry, the federal government increase its financial and personnel support of the Canadian negotiating team leading up to the conclusion of such an agreement.
CIF/IFC Letters

\section{SAF President Seeks More Cooperation with CIF}

\author{
Dr. Peter Murphy, President \\ Canadian Institute of Forestry \\ Department of Forest Science \\ University of Alberta \\ Edmonton, Alberta T6G 2H1
}

Dear Peter:

Now that the dust has settled from our great Alaskan Convention, I wish to sincerely thank you and the Canadian Institute of Forestry for bestowing upon me the Tree of Life Award. Words can not describe my total surprise or express my humble gratitude to be accorded this honor. It truly has very special meaning since my first professional paper was presented at the joint $1967 \mathrm{CIF} / \mathrm{SAF}$ convention in Ottawa.

Peter, it was a real pleasure to meet and work with you and the CIF staff on this convention - an absolutely successful cooperative effort. Many have stated that we should encourage greater participation between our organizations. I support that idea. While in Anchorage, Keith Jennings indicated that the Australians would look favorable upon participating in a joint convention with us. A potential site could be Hawaii; I will explore the idea of hosting such a feature joint conference with our Hawaii State Society chair.

Again Peter, thanks for the award; it was definitely my pleasure to join with you in hosting the Anchorage Convention.

Sincerely, John W. Moser, Jr.

President Society of American Foresters 